\title{
Gas Permeability Improvement Mechanism at the Blast Furnace Cohesive Zone by Mixed Coke Charging in Ore Layer and Effect of Coke Mixing for Different Cohesive Zone Condition on Gas Permeability
}

\author{
Masahiro YAKEYA, ${ }^{*}$ Akito KASAI, Rikizo TADAI and Kentaro NOZAWA \\ R\&D Laboratory, KOBE STEEL, LTD., Onoe-cho, Kakogawa, 675-0023 Japan. \\ (Received on October 30, 2019; accepted on March 6, 2020)
}

\begin{abstract}
A major operational problem in increasing pulverized coal rate and decreasing coke rate must be the increased pressure drop or the worsened gas permeability at the lower part of the blast furnace. In order to decrease the pressure drop at the blast furnace cohesive zone (CZ) under low coke rate operation, this study has focused on mixed coke charging in the ore layer. Results obtained by numerical analysis and experiments are as follows:

(1) Numerical analysis using DEM (Discrete Element Method) clarified the change in the cohesive ore bed structure with mixed coke charging and the formation conditions of gas path in the bed. Also, DEMCFD (DEM and Computational Fluid Dynamics) analysis enabled us to find a gas permeability improvement mechanism and an optimum coke mixing ratio for different $\mathrm{CZ}$ conditions before applying the technology.

(2) Experiments in blast furnace hot model demonstrated the decreased pressure drop at the CZ by mixed coke charging in the ore layer. The experimental results abided by the numerical analysis results.
\end{abstract}

KEY WORDS: ironmaking; blast furnace; cohesive zone; mixed coke charging; coke slit; gas permeability.

\section{Introduction}

Recently, low coke rate and high PC (Pulverized Coal) rate operation ${ }^{1)}$ has become more common to reduce hot metal costs in blast furnace ironmaking process. One significant operational problem in low coke rate along with high PC rate is the increased pressure drop or worsened gas permeability especially at the lower part of blast furnace (cohesive zone (CZ), deadman, bird's nest) by decreasing the amount of spacer coke and increasing gas volume in the furnace. The phenomenon about worsening gas permeability around the $\mathrm{CZ}$ is caused by a relatively thinning coke slit (coke layer at $\mathrm{CZ}$ ) under increasing $\mathrm{O} / \mathrm{C}$ (charging mass ratio of ore to coke). To improve gas permeability of $\mathrm{CZ}$, several improvements have already been carried out: improving the reducibility of fired ore, ${ }^{2)}$ controlling the burden distribution such as center charged coke, ${ }^{3)}$ charging the ore layer with mixed coke, ${ }^{4-7)}$ etc.

Nut coke (small size coke) mixing in ore layer is conventionally well-practiced method to improve reduction efficiency, however, techniques for mixing large amounts of lump coke that mixes more than the amount of solution loss carbon in addition to small size coke are also being studied in recent years for improving gas permeability of

\footnotetext{
* Corresponding author: E-mail: yakeya.masahiro@kobelco.com DOI: https://doi.org/10.2355/isijinternational.ISIJINT-2019-699
}

CZ. $\left.{ }^{89}\right)$ The Chiba No.6 Blast Furnace is equipped with a large amount of mixture of small size coke and lump coke at a rate of $100 \mathrm{~kg} / \mathrm{tp}$ or more and realizing high production and low reducing agent rate operation under low fired ore ratios. ${ }^{10)}$ In addition, the effect of mixed lump coke charging in the ore layer on gas permeability is mainly being studied using laboratory experiments ${ }^{10)}$ or DEM-CFD models. ${ }^{11-13)}$

Reduction under load experiments ${ }^{14)}$ have been conducted mainly specializing in the evaluation of reducibility and gas permeability of ore layers under prescribed reducing conditions. On the other hand, Ichikawa et al. ${ }^{15)}$ developed CZ simulator to load vertically and to attain input gas flow parallel to sample layer, which could evaluate with more accuracy the gas permeability of CZ (ore cohesive layer + coke slit). They evaluated the effect of coke slit thickness (coke layer thickness) and mixed coke charging in ore layer on gas permeability and clarified that the infiltration layer thickness per interface of the cohesive ore decreases and the void of the cohesive layer increases by mixed coke charging in ore layer, while the width of $\mathrm{CZ}$ studied remained constant.

Some DEM-CFD model analysis ${ }^{11-13)}$ have revealed that the gas flow around $\mathrm{CZ}$ was affected by not only the coke mixing rate but also by $\mathrm{CZ}$ conditions such as coke rate ${ }^{12)}$ and $\mathrm{CZ}$ thickness. ${ }^{11)}$ Although those results suggest that the size of $\mathrm{CZ}$ (horizontal distance and thickness of the cohesive layer, coke slit thickness) is an important factor to 
evaluate the gas permeability change and hence the practical effectiveness by mixed coke charging, no study adequately investigate its effect with detailed analysis of void distributions at the surface vicinity of a coke particle in ore layer.

In the present study, the void structure change of the ore cohesive layer by mixed coke charging in ore layer was investigated in detail by DEM analysis, and the mechanism of gas "channel" formation based on calculated results was newly proposed. In addition, the effect of the coke mixing ratio and $\mathrm{CZ}$ condition (horizontal distance of cohesive layer, coke slit thickness) on gas permeability were revealed by DEM-CFD model analysis, which also coincides with the gas permeability change obtained by the comprehensive evaluation approach using a blast furnace hot model experiment.

\section{Gas Permeability Improvement Mechanism of Ore Cohesive Layer by Mixed Coke Charging}

Figures 1(a) and 1(b) show the interruption test results during the reduction test under load demonstrating a change in the packed bed structure of the ore cohesive layer at previously reported conditions. ${ }^{7}$ The sample is iron ore pellets and the interruption temperatures are (a) $1300^{\circ} \mathrm{C}$ and (b) $1400^{\circ} \mathrm{C}$ in $\mathrm{CZ}$ temperature range. At any temperature, the pellets can be discriminated individual particles. As the temperature increases, the pellet particles are crushed, and the layer shrinkage progresses, and void fraction in the packed layer is reduced.
Figures 1(c), 1(b) shows the results of an interruption test in the temperature range at maximum pressure drop value in a permeability experiment using a quasi ore $(\varphi 6.1 \mathrm{~mm} \times$ h $4.3 \mathrm{~mm}$, average particle size $\mathrm{Do}=5.0 \mathrm{~mm}$, softening and melting temperature $=110-130^{\circ} \mathrm{C}$ ) which consist of polyethylene and wax as previous report. ${ }^{16)}$ The sample (c) is quasi ore $100 \mathrm{vol} \%$, the quasi ore particles are softened and melted in a state which can be identified at the lower part of the packed bed and dripping of liquid is not observed at this point. In the case of mixed coke charging in the ore layer (d) (mixed coke average particle size $\mathrm{Dc}=13.5 \mathrm{~mm}$, coke to ore particle size ratio $\mathrm{Dc} / \mathrm{Do}=2.7$, coke mixing ratio $=16 \mathrm{vol} \%$ ), quasi ore particles in the coke vicinity are more softened and melted than the rest of the bed indicating that gas ascended preferably around the region.

In both experiments, since the ore particles in the cohesive layer are in a state that can be identified as particles, changes in the packed bed structure and void structure of the cohesive layer can safely be simulated by DEM. Based on the observation results in Fig. 1(d), as shown in Fig. 2, the packed bed structure of the ore cohesive layer during the improvement of gas permeability by mixed coke charging has a high void fraction region around the mixed coke in the ore layer, and the nearest distance between the mixed coke $D_{\text {nb }}$ approaches to form a gas path enabling gas flow in mixed layer, the mechanism of which was further studied through DEM analysis.

Here, the fundamental equations in DEM consist of a translational motion equation and a rotational motion equa-

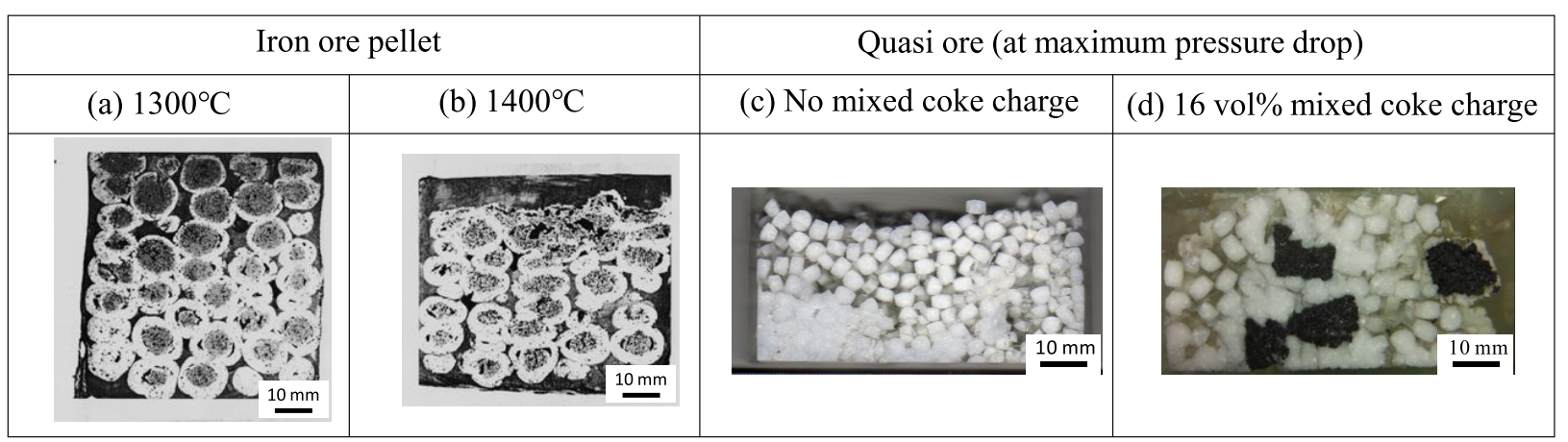

Fig. 1. Cross sectional views of cohesive layer. (Online version in color.)

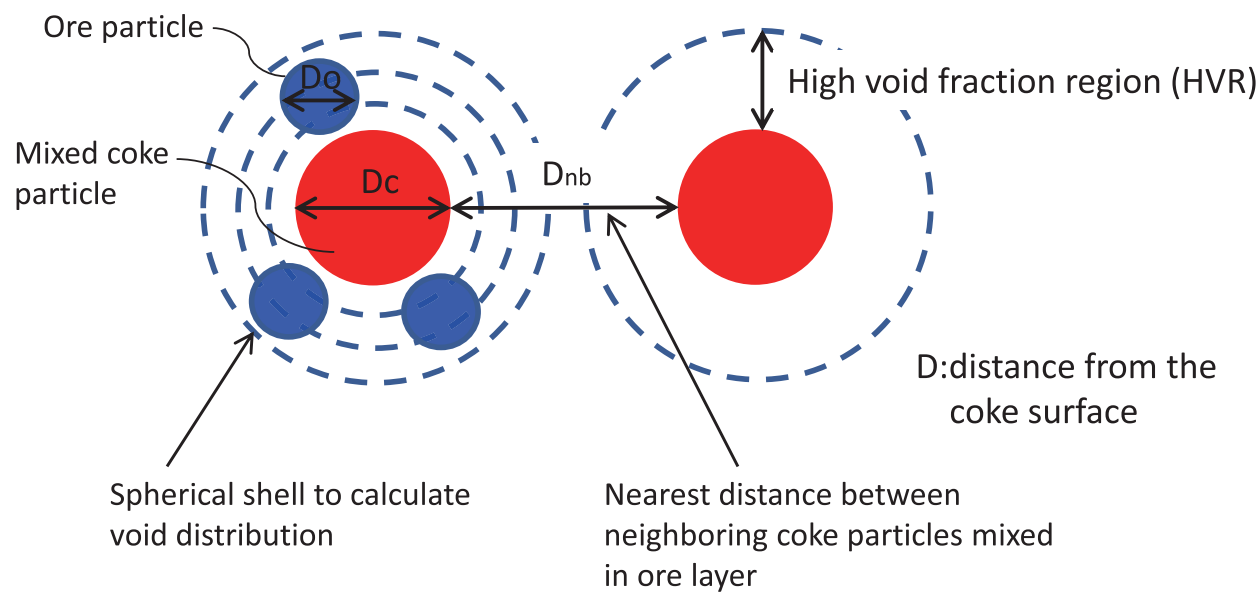

Fig. 2. Parameters to describe void structure in ore-coke mixed layer. 
tion, which uses the stress and moment from the contact points between individual particles and between particles and the furnace wall as previous report. ${ }^{17)}$ Drag force is calculated by a Voigt model, which is approximated by a spring, dashpot, and frictional slider.

The void fraction in the surface vicinity of mixed coke particle was calculated by the method adopted in previous study ${ }^{18)}$ cutting the area from the surface layer of the coke particles into a spherical shell in Fig. 2 after placing a given size coke particle in the center of the ore packed bed and compressing the packed bed with a load of $0.1 \mathrm{MPa}$ by simulating a softened cohesive layer.

Table 1 shows DEM calculation conditions. The particle size of the ore (diameter Do) was changed to calculate under different Dc/Do conditions. Young's modulus was adjusted as shown in Table 1 so that the average void fraction with no coke mixture was approximately 0.2 .

Figure 3 shows the relationship between the relative distance from the coke surface $\mathrm{D} /$ Ro and average void fraction of shell region at designated position. A high void fraction region HVR that exceeds distinctively the average void fraction of ore bed with no coke mixture was estimated to

Table 1. DEM calculation conditions.

\begin{tabular}{lcc}
\hline \multirow{1}{*}{ Parameter } & \multicolumn{2}{c}{ Value } \\
\cline { 2 - 3 } & Ore & Coke \\
\hline Particle diameter, D (mm) & variable & 8.0 \\
Particle density $\left(\mathrm{kg} / \mathrm{m}^{3}\right)$ & 3000 & 1000 \\
$\begin{array}{l}\text { Friction coefficient (-) } \\
\text { (Particle-Particle) }\end{array}$ & 0.3 & 0.3 \\
$\begin{array}{l}\text { Friction coefficient (-) } \\
\text { (Particle-Wall) }\end{array}$ & 0.3 & 0.3 \\
Poisson's ratio (-) & 0.24 & 0.24 \\
Young's module (GPa) & 1.0 & 0.01 \\
Time step (s) & \multicolumn{2}{c}{$1.0 \times 10^{-5}$} \\
Duration (s) & \multicolumn{2}{c}{3.0} \\
\hline
\end{tabular}

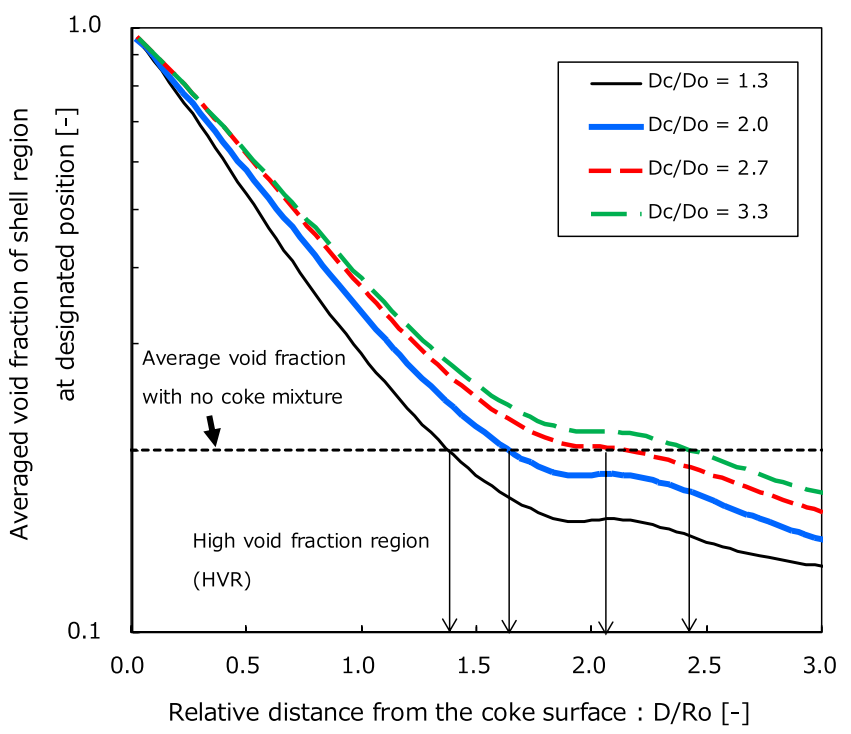

Fig. 3. Calculated distributions of void fractions in the surface vicinity of mixed coke particle after compressed conditions for varying Dc/Do. (Online version in color.) exist around the mixed coke particle and to extend farther in increased Dc/Do.

The more detailed relationship is shown in Fig. 4 between the HVR around the mixed coke particles and the particle size ratio Dc/Do. Although roughly the HVR increases with $\mathrm{Dc} / \mathrm{Do}$, its effect on HVR seems complicated and requires Dc/Do well over 1.8 to realize the distinguishably high HVR formation.

The nearest neighboring distance $\mathrm{D}_{\mathrm{nb}}$ for every single coke particle was also calculated for all coke particle at different mixing ratios after placing and compressing the packed bed (ore particles and mixed coke particles) with a load of $0.1 \mathrm{MPa}$ by simulating a softened cohesive layer. Figure 5 shows the relationship between the coke mixing ratio in ore layer and the dimensionless value $\mathrm{D}_{\mathrm{nb}} / \mathrm{Ro}$ of the nearest distance between the mixed coke particles $D_{n b}$ at $\mathrm{Dc} / \mathrm{Do}=2.7$. As the coke mixing ratio increases, $\mathrm{D}_{\mathrm{nb}} / \mathrm{Ro}$ decreases sharply until it reaches almost a saturated value about 1.0 at mixing ratio 15 vol\% or higher. From Fig. 3, the high void region HVR is about $\mathrm{D} / \mathrm{Ro} \leqq 2.0$ under the condition of $\mathrm{Dc} / \mathrm{Do}=2.7$. This suggests that the possibility of forming a stable gas path is increased when the nearest coke particles exist at $\mathrm{D}_{\mathrm{nb}} / \mathrm{Ro} \leqq 4.0$ range which conditions

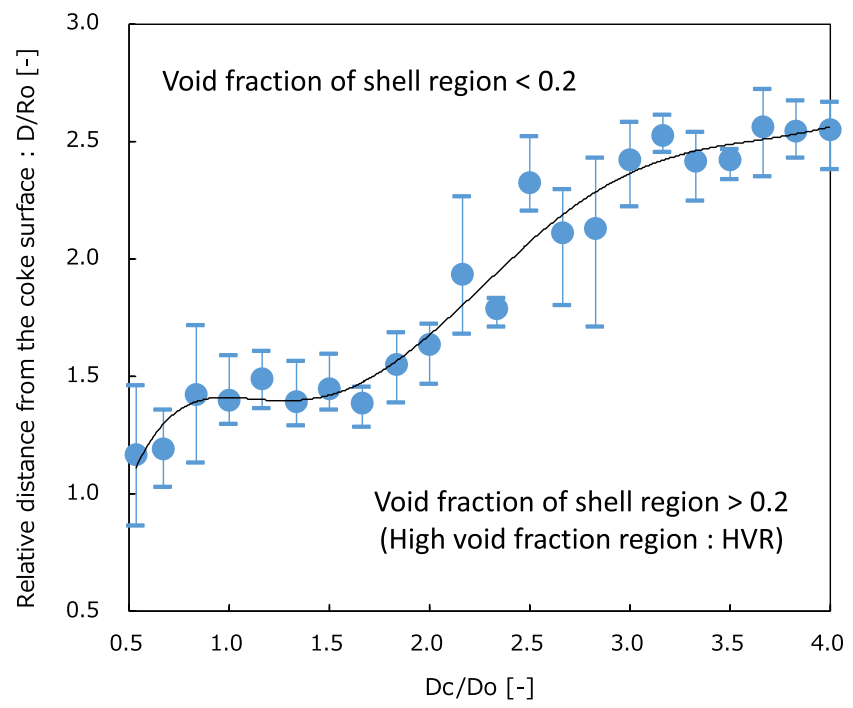

Fig. 4. Effect of De/Do on HVR. (Online version in color.)

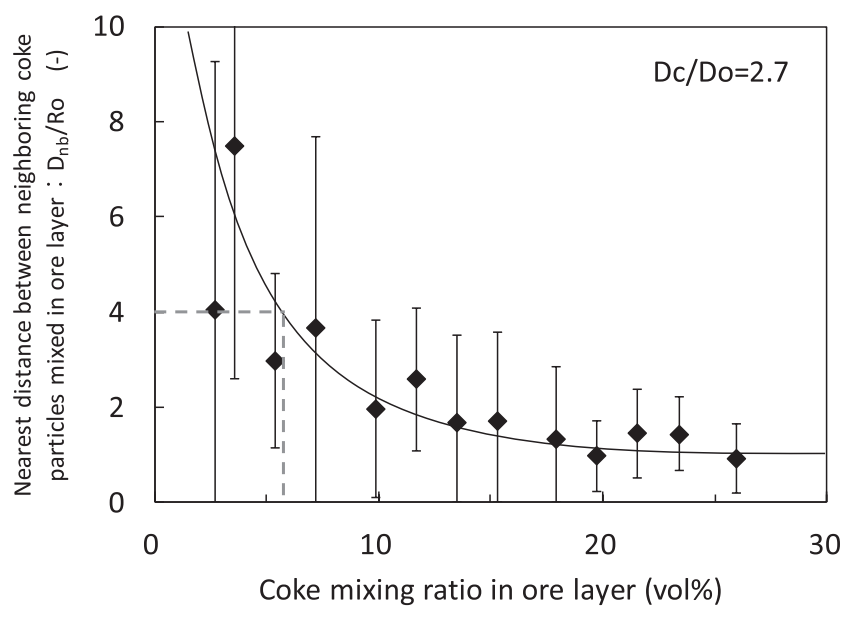

Fig. 5. Effect of coke mixing ratio on the nearest distance between neighboring coke particles mixed in ore layer. 
will be realized at coke mixing ratio of 6 vol\% or higher.

The idea was to clarify the minimum required ratio of coke mixing in order to form stable gas path connections between mixed coke particles which are quite relevant to the particular space distributions formed around coke particles residing in ore layer.

\section{Effects of Coke Mixing Ratio and Cohesive Zone Conditions on Gas Permeability}

The gas permeability of $\mathrm{CZ}$ was investigated by numerical analysis combining the Discrete Element Method (DEM) and Computational Fluid Dynamics (CFD). ${ }^{11-13,18,19)}$ The fundamental equations of fluid motion are equation of continuity (1) and equation of motion (2).

Equation of continuity:

$$
\frac{\partial}{\partial \mathrm{t}} \varepsilon+\frac{\partial}{\partial \mathrm{x}_{\mathrm{j}}}\left(\varepsilon \mathrm{u}_{\mathrm{j}}\right)=0
$$

Equation of motion:

$$
\frac{\partial}{\partial \mathrm{l}}\left(\varepsilon \mathrm{u}_{\mathrm{i}}\right)+\frac{\partial}{\partial \mathrm{x}_{\mathrm{j}}}\left(\varepsilon \mathrm{u}_{\mathrm{i}} \mathrm{u}_{\mathrm{j}}\right)=-\frac{\varepsilon}{\rho_{g}} \frac{\partial \mathrm{p}}{\partial \mathrm{x}_{\mathrm{i}}}+\mathrm{f}_{\mathrm{pi}}
$$

Here, $\mathrm{p}, \mathrm{u}, \varepsilon$ and $\rho_{\mathrm{g}}$ are pressure, fluid velocity, porosity, and fluid density.

The calculation target area is the coke layer and the upper and lower half of ore layers shown in Fig. 6(a). The diameter of the ore particles Do is $3.0 \mathrm{~mm}$, and the diameter of the large coke particles and the mixed coke particles $\mathrm{Dc}$ is $8.0 \mathrm{~mm}(\mathrm{Dc} / \mathrm{Do}=2.7)$. The $\mathrm{O} / \mathrm{C}=5.0$, and these were alternately packed in layers into a container which width set the melting zone width and was variable for each case study. The coke particles were mixed into the ore layer by a predetermined amount under a constant coke rate (= layered charge coke + mixed coke). After compressing the packed bed by applying a load of $0.1 \mathrm{MPa}$ from above and simulating an ore cohesive layer, the pressure drop was calculated by flowing gas at $1.0 \mathrm{~m} / \mathrm{s}$ horizontally (Fig. 6(b)).

The features of the model are the following: (1) Young's modules of ore were reduced enough to simulate layer shrinkage ${ }^{20)}$ while adopting the maximum overlapping limit at $40 \%$ of ore radius to avoid computational instability. (2)
The Young's modulus of the wall was adjusted to prevent a high void area formation near the wall during the gas permeability calculation. (3) The gas permeability was calculated by sequentially calculating the local average void fraction after dividing the packed bed into small cells. As in the previous study, ${ }^{18}$ the overlapped particles preserved their volume at the central coordinates as representative points, so that the volume extinguished in the DEM calculation through overlapping was restored by decreasing the local void fraction in the CFD calculation. The pressure drop was calculated using the Ergun equation.

Table 2 shows particle numbers for DEM-CFD calculation. The particle size of the ore (diameter Do) is $3.0 \mathrm{~mm}$, the particle size of coke (diameter Dc) is $8.0 \mathrm{~mm}$ and Dc/Do is 2.7 .

Figure 7 shows the calculation results of the gas permeability of $\mathrm{CZ}$ in the DEM-CFD model. The width of the cohesive layer (horizontal distance) and the coke slit thickness before applying coke mixing were changed to investigate the influence on the effect of coke mixture. The change in pressure drop on the vertical axis is relatively shown to the 0 vol\% mixing under the conditions (a) to (c). When the relative length MZW (= width of the cohesive layer/radius of the ore particle Ro) of the cohesive layer is small $(\mathrm{MZW}=27)$, the increase of coke mixing makes the relative change in pressure drop gradually decrease to reach a constant low in spite of the relative thickness CLT (=coke slit thickness at $0 \mathrm{vol} \%$ mixing ratio/ore particle radius Ro) of the coke slit. In the case of increased MZW of 40 and 53 , the relative change in pressure drop initially decreases with the increase of the coke mixing ratio, but it starts to increase when the mixing ratio further increases. When

Table 2. Particle numbers for DEM-CFD calculation in Fig. 7.

\begin{tabular}{ccrcc}
\hline & & \multicolumn{3}{c}{ CLT } \\
\cline { 3 - 5 } & & \multicolumn{1}{c}{15} & 25 & 35 \\
\hline \multirow{3}{*}{ MZW } & 27 & $80 / 2546$ & $134 / 4244$ & $188 / 5941$ \\
& 40 & $120 / 3819$ & $201 / 6366$ & $282 / 8912$ \\
& 53 & $161 / 5092$ & $268 / 8488$ & $376 / 11883$ \\
\hline
\end{tabular}

Particle numbers (Coke particles/Ore particles)

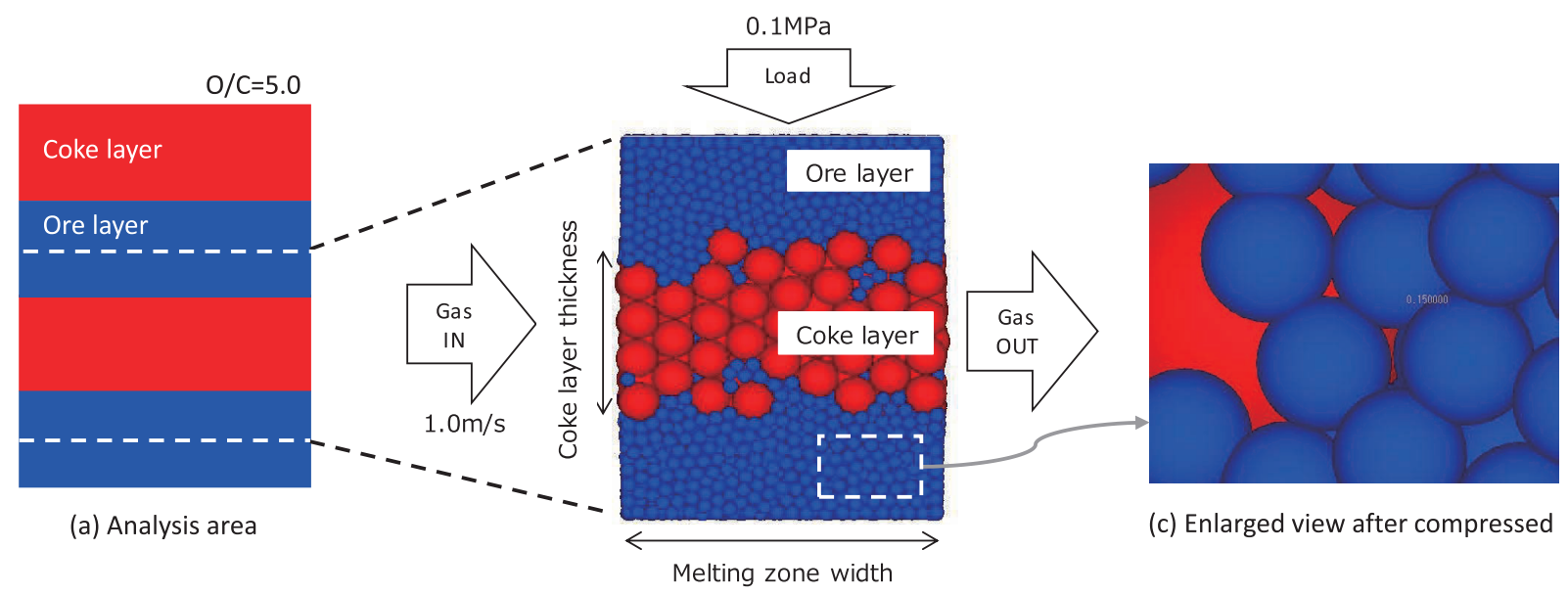

(b) Numerical analysis method of DEM-CFD model

Fig. 6. Simulated field of DEM-CFD analysis. 

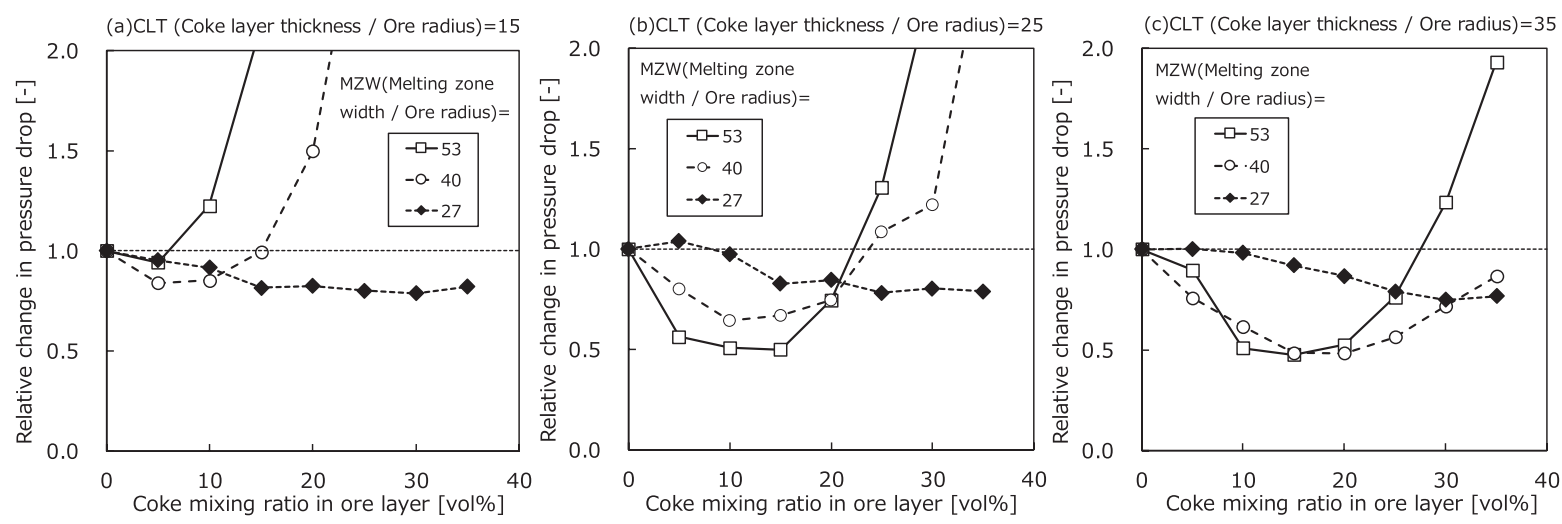

Fig. 7. Comparison of relative pressure drop with different cohesive zone size and coke mixing ratio.
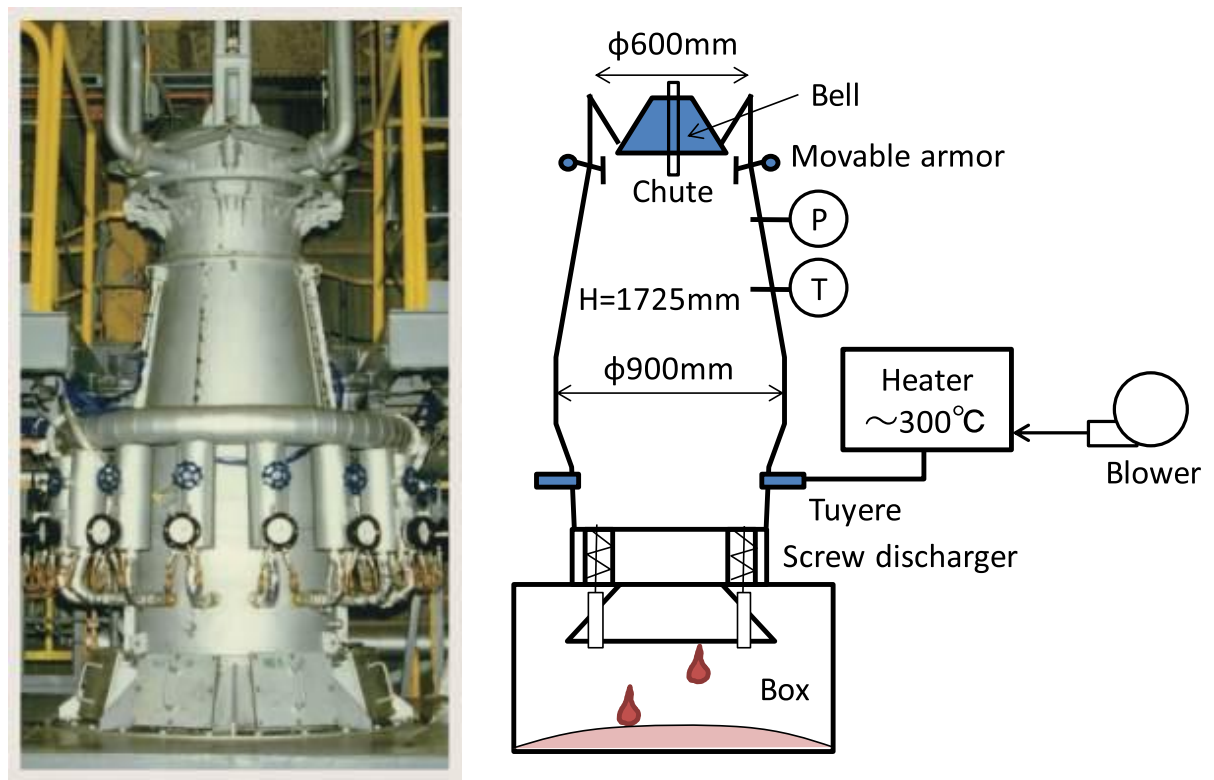

Fig. 8. Experiment apparatus of blast furnace hot model. (Online version in color.)

the CLT increases (the coke slit thickness increases), the amount of decrease in the relative change in pressure drop for $\mathrm{MZT}=40,53$ increases to give wider range of coke mixing ratio where it is possible to attain better gas permeability than the case with no coke mixture.

The above results clarified that the pressure drop of $\mathrm{CZ}$ during mixed coke charging in ore layer is affected not only by the mixed coke conditions (mixed coke size and coke mixing ratio) but also by $\mathrm{CZ}$ conditions (horizontal distance of the cohesive layer, coke slit thickness).

\section{Comprehensive Evaluation of Gas Permeability Using Blast Furnace Hot Model}

In Chapter 3, the mathematical model calculation has been performed focusing on $\mathrm{CZ}$ with gas flow simply limited to the horizontal direction. Although this simplified model could clarify the effect of coke mixing ratio as well as $\mathrm{CZ}$ conditions (horizontal distance of fused layer, coke slit thickness) on gas permeability, the three dimensional gas and mass flow in the actual blast furnace could form variable shapes and size conditions of pairs of coke slit and softening ore in $\mathrm{CZ}$ and then requires with a practical view point, to validate the above-mentioned ideas via numerical analysis, three-dimensional gas and mass flow investigation.
For this reason, a comprehensive study using a blast furnace hot model was carried out.

Figure 8 shows the experimental apparatus of blast furnace hot model (scale $1 / 17$ of Kakogawa No. 3 blast furnace (1st)). The model size are as follows: throat diameter $=\varphi 600 \mathrm{~mm}$, belly diameter $=\varphi 900 \mathrm{~mm}$, hearth diameter $=\varphi 840 \mathrm{~mm}$, shaft height $=1088 \mathrm{~mm}$, belly height $=147 \mathrm{~mm}$, bosh height $=200 \mathrm{~mm}$, effective height $=1725 \mathrm{~mm}$. The rig is equipped with 16 tuyeres, charging system of bell movable armor and a center coke charging chute. The burden was discharged into the box by screw feeders under raceways.

The sample is a previously reported quasi ore $(\varphi 6.1 \mathrm{~mm} \times$ h $4.3 \mathrm{~mm}$, average particle size Do $=5.0 \mathrm{~mm})^{15)}$ and coke, and the sample size is about $1 / 3$ scale of the actual blast furnace burden. Layered charge coke, mixed charge coke and center charged coke are all the same size (10-20 mm).

The blast conditions were as follows: blast temperature $=170^{\circ} \mathrm{C}$, blast volume $=10.3 \mathrm{Nm}^{3} / \mathrm{min}$, and heat flow ratio $=0.82$. The heat flow ratio of experiment is similar to the actual blast furnace. There are 4 charging conditions: layered charging (coke mixing ratio $=0$ vol\%) and mixed coke charging in the ore layer (coke mixing ratio $=11.7$ vol $\%, 25.4$ vol $\%, 31.8$ vol $\%$, particle size ratio $\mathrm{Dc} / \mathrm{Do} \doteqdot 3.0)$. The coke rate (=layered charge coke + mixed charge 
coke + center charged coke) is constant (equivalent to $306 \mathrm{~kg} / \mathrm{tp}$ ) under all conditions.

At experiment, wall temperature and pressure in the furnace were measured continuously. The burden in the hot model was quenched in a steady state after the initial burden was replaced. At the decision study, boundaries between melting part and no melting part of quasi ore layer were marked by painting black.

Figure 9 shows a cross-sectional photograph of the dissection study, comparing the layered charging (coke mixing ratio $=0$ vol $\%$ ) and the mixed coke charging (coke mixing ratio $=11.7$ vol $\%, 31.8 \mathrm{vol} \%$ ). The shape of $\mathrm{CZ}$ at layered charging and the coke mixing ratio $=11.7 \mathrm{vol} \%$ are both inversed V-shaped. At layered charging, the boundary between the cohesive layer and the coke slit is clear, while at mixed coke charging (coke mixing ratio $=11.7 \mathrm{vol} \%$ ), the coke slit is thin, and the boundary is unclear, and it is being integrated with the cohesive layer literally to form a mixed zone. Focusing on the detailed gas flow (gas distribution) in $\mathrm{CZ}$, in the case of layered charging, the ore layer was melted from the surface in contact with the coke (upper and lower surfaces of the ore layer) because hot gas preferentially flows through the coke slit with a small gas permeability resistance. In the case of coke mixing ratio $=11.7 \mathrm{vol} \%$, it was found that the ore layer was melted by reduced gas flow resistance due to the formation of gas path and hot gas flows through the ore layer. On the other hand, at the mixing ratio $=31.8 \mathrm{vol} \%$ the shape of $\mathrm{CZ}$ became asymmetrical, it disturbed the circumferential balance, and the quasi ore melted over a wide range.

Figure 10(a) shows a comparison of the furnace pressure distribution in the height direction under the conditions of coke mixing ratio $=0.0$ vol $\%$ and 11.7 vol $\%$, and Fig. $10(\mathrm{~b})$ shows the relative pressure drop of $\mathrm{CZ}$ assuming 1.0 at coke mixing ratio $=0$ vol $\%$. The relative pressure drop distribution (a) in the height direction rises rapidly from the top layer of $\mathrm{CZ}$ to the tuyere level (Height $=0)$, while at mixing ratio $=11.7 \mathrm{vol} \%$ the pressure drop of the region decreased about $15 \%$ compared to the case of layered charging. The relative pressure drop of $\mathrm{CZ}$ (b) was the lowest at the coke mixing ratio $=11.7 \mathrm{vol} \%$. At coke mixing ratio $=31.8 \mathrm{vol} \%$, the relative pressure drop was greater than in the layered
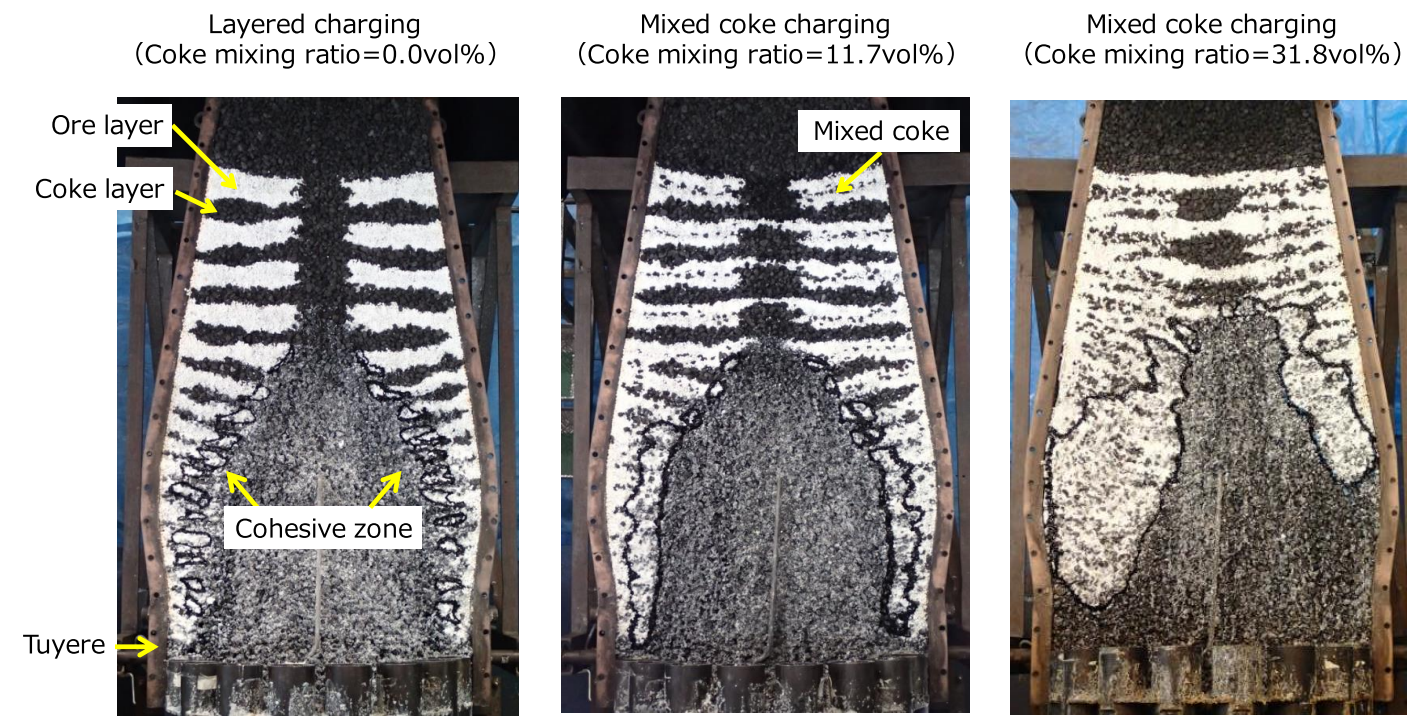

Fig. 9. Effect of coke mixing ratio on cohesive zone. (Online version in color.)
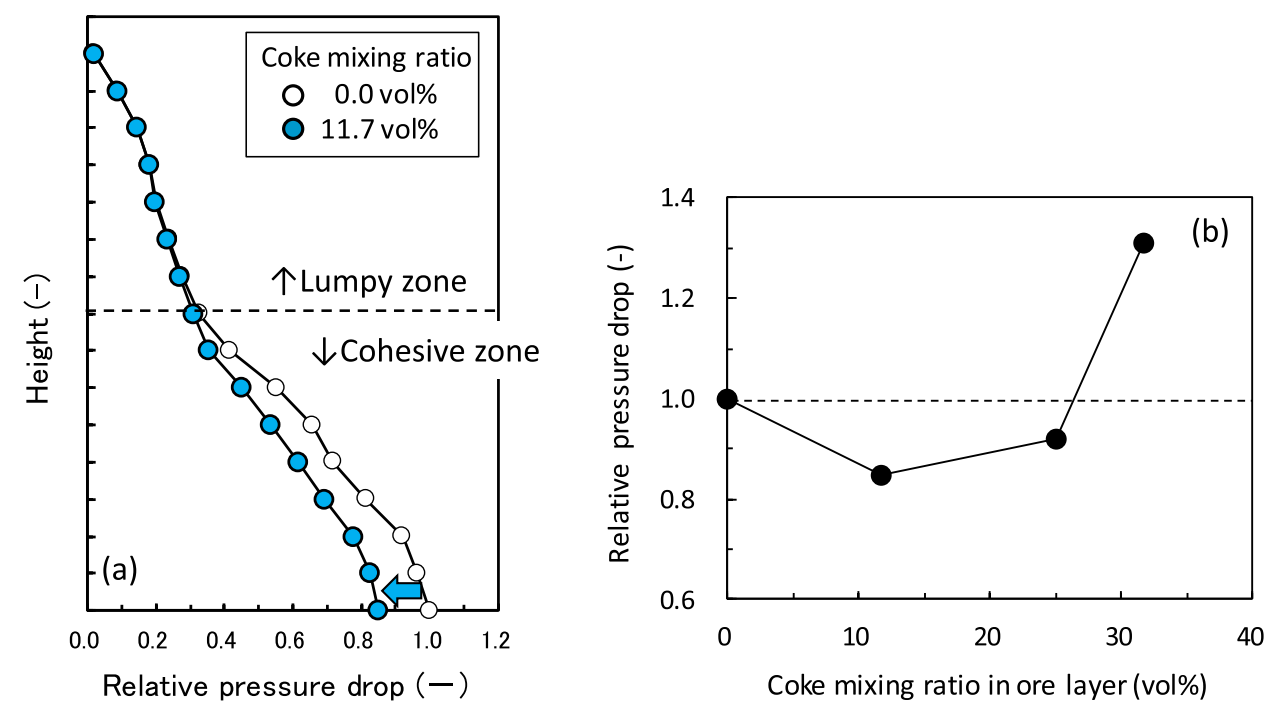

Fig. 10. Effect of coke mixing ratio on pressure drop at cohesive zone. (Online version in color.) 
charging due to the disturbance of the circumferential balance and the expansion of $\mathrm{CZ}$ resulting from the irrevocably instable gas flow.

In the experiment, CLT was 13-29 and MZW was 26-39. Although there is a slight difference in $\mathrm{O} / \mathrm{C}$, the experimental results in Fig. 9(b) tend to be relatively close to the calculated results of $\mathrm{MZW}=40$ at $\mathrm{CLT}=15$ or $\mathrm{MZW}=40$ at $\mathrm{CLT}=25$ in Fig. 7. This may indicate that there existed the gas permeability controlling part or pair of $\mathrm{CZ}$ in whole softening-melting area with various size and shape cohesive parts coexisting in three dimensional system. The "representative" zone structure is supposed to be influenced and be varied for distinct operational conditions, however, this information on particular blast furnace before applying coke mixture is of significant importance to adopt the technology in most practically optimum and operationally stable way.

\section{Conclusions}

The effect of mixed coke conditions (mixed coke size and coke mixing ratio) and cohesive zone (CZ) conditions (horizontal distance of cohesive layer, coke slit thickness) on void structure change of ore cohesive layer and $\mathrm{CZ}$ gas permeability were investigated thoroughly to improve the gas permeability of blast furnace $\mathrm{CZ}$ by mixed coke charging.

The following is a summary of obtained results:

(1) When lump coke with a particle size ratio Dc/Do of mixed coke and ore of 1.8 or more is mixed into the ore layer, a high void region is formed around the mixed coke, and when Dc/Do increases, the high void fraction region becomes wide. The increased coke mixing makes neighboring coke particles come closer and may start connecting gas channels after the certain neighboring distance depending on the degree of high void region formed around the mixed coke particle.

(2) The pressure drop of $\mathrm{CZ}$ at mixed coke charging in ore layer is affected not only by the mixed coke conditions (mixed coke size and coke mixing ratio) but also by $\mathrm{CZ}$ conditions (horizontal distance of cohesive layer and coke slit thickness). The relative effect of these factors on $\mathrm{CZ}$ gas permeability was quantitatively determined, and the proper range in which gas permeability could be improved by mixed coke charging in ore layer was clarified.

(3) The gas permeability improvement effect by mixed coke charging was demonstrated in the blast furnace hot model experiment indicating the appropriate coke mixing range also for three-dimensional condition, from which results the possible existence of a gas permeability controlling set of CZ structure representing a particular operation condition was also suggested and was of great importance in order to practically estimate the coke mixing effect on improving gas permeability.

\section{REFERENCES}

1) R. Ito, Y. Yoshida, K. Hoshino, F. Noma and T. Suzuki: Kobe Steel Eng. Rep., 50 (2000), No. 3, 6 (in Japanese).

2) R. Nishida, O. Tsuchiya, T. Uenaka, T. Satoh, K. Aketa and T. Nishida: Kobe Steel Eng. Rep., 34 (1984), No. 4, 28 (in Japanese).

3) M. Shimizu, Y. Kimura, S. Inaba, R. Hori, K. Kuwano and F. Noma: Kobe Steel Eng. Rep., 41 (1991), No. 4, 11 (in Japanese).

4) Y. Shimomura, K. Kushima, F. Sato and S. Arino: Tetsu-to-Hagané, 62 (1976), S404 (in Japanese).

5) M. Gono, K. Iwatsuki, M. Takasaki, K. Noshima and T. Miwa: Tetsuto-Hagané, 68 (1982), S709 (in Japanese).

6) T. Sato, T. Sumigama, A. Yamaguchi, K. Kimura, A. Shimomura and S. Furuya: Tetsu-to-Hagané, 70 (1984), S777 (in Japanese).

7) M. Isobe, T. Sugiyama and S. Inada: Proc. 6th Int. Iron and Steel Congr., ISIJ, Tokyo, (1990), 439.

8) A. Sato, M. Arizuka, Y. Yamagata, H. Miyagawa, T. Goto and I. Mizuguchi: CAMP-ISIJ, 5 (1992), 1064 (in Japanese).

9) S. Watakabe, K. Takeda, H. Nishimura, S. Goto, N. Nishimura, T. Uchida and M. Kiguchi: ISIJ Int., 46 (2006), 513.

10) S. Watakabe, A. Murao and S. Goto: JFE Giho, 22 (2008), 49 (in Japanese).

11) T. Ariyama, S. Matsuhashi, S. Natsui, T. Kon, S. Ueda and R. Inoue: CAMP-ISIJ, 25 (2012), 956, CD-ROM (in Japanese).

12) S. Matsuhashi, H. Kurosawa, S. Natsui, T. Kon, S. Ueda, R. Inoue and T. Ariyama: ISIJ Int., 52 (2012), 1990.

13) T. Kon and H. Saima: CAMP-ISIJ, 32 (2019), 174, CD-ROM (in Japanese)

14) M. Sato, T. Yamamoto and M. Sakurai: JFE Giho, 32 (2013), 18 (in Japanese).

15) K. Ichikawa, Y. Kashihara, N. Oyama, T. Hirosawa, J. Ishii, M. Sato and H. Matsuno: Tetsu-to-Hagané, 102 (2016), 1 (in Japanese).

16) S. Ikuta, A. Kasai and K. Nozawa: CAMP-ISIJ, 29 (2016), 114, CDROM (in Japanese).

17) T. Ariyama, S. Natsui, T. Kon, S. Ueda, S. Kikuchi and H. Nogami: ISIJ Int., 54 (2014), 1457.

18) S. Natsui, H. Nogami, S. Ueda, J. Kano, R. Inoue and T. Ariyama: ISIJ Int., 51 (2011), 41.

19) T. Kawaguchi, T. Tanaka and Y. Tsuji: Trans. Jpn. Soc. Mech. Eng. $B, 61$ (1995), 3169 (in Japanese).

20) S. Ueda, S. Natsui, Z. Fan, H. Nogami, R. Soda, J. Kano, R. Inoue and T. Ariyama: ISIJ Int., 50 (2010), 981. 